\title{
Effect of Switching on Metal-Organic Interface Adhesion Relevant to Organic Electronic Devices
}

\author{
Babaniyi Babatope $^{1 *}$, Akogwu Onobu ${ }^{2}$, Olusegun O. Adewoye ${ }^{3}$, Winston O. Soboyejo ${ }^{2,3}$ \\ ${ }^{1}$ Department of Physics, Obafemi Awolowo University, Ile-Ife, Nigeria \\ ${ }^{2}$ Department of Mechanical and Aerospace Engineering, Princeton University, Princeton, USA \\ ${ }^{3}$ Materials Science and Engineering Department, African University of Science and Technology, Abuja, Nigeria \\ Email: "niyibabatope@gmail.com
}

Received September 4, 2013; revised October 8, 2013; accepted October 16, 2013

Copyright (C) 2013 Babaniyi Babatope et al. This is an open access article distributed under the Creative Commons Attribution License, which permits unrestricted use, distribution, and reproduction in any medium, provided the original work is properly cited.

\begin{abstract}
Considerable efforts are currently being devoted to investigation of metal-organic, organic-organic and organic-inorganic interfaces relevant to organic electronic devices such as organic light emitting diode (OLEDs), organic photovoltaic solar cells, organic field effect transistors (OFETs), organic spintronic devices and organic-based Write Once Read Many times (WORM) memory devices on both rigid and flexible substrates in laboratories around the world. The multilayer structure of these devices makes interfaces between dissimilar materials in contact and plays a prominent role in charge transport and injection efficiency which inevitably affect device performance. This paper presents results of an initial study on how switching between voltage thresholds and chemical surface treatment affects adhesion properties of a metal-organic (Au-PEDOT:PSS) contact interface in a WORM device. Contact and Tapping-mode Atomic Force Microscopy (AFM) gave surface topography, phase imaging and interface adhesion properties in addition to SEM/EDX imaging which showed that surface treatment, switching and surface roughness all appeared to be key factors in increasing interface adhesion with implications for increased device performance.
\end{abstract}

Keywords: AFM; Interface; Adhesion Force; Organic Electronics; Voltage Switching; Organic Memory Devices; Surface Treatment

\section{Introduction}

The investigation of interfaces between dissimilar organic-metal, organic-organic and organic-inorganic materials which are inherent in the devices made from them has been intensified in recent times. The interface phenomena are thus crucial towards the development, understanding and improvement of organic-based semiconductor electronic device [1-14] applications such as organic light emitting devices (OLEDs) [15-18], organic photovoltaic devices [19-21], organic thin film transistor devices [22-27] and organic spin electronic devices in which the transport and control of spin polarized information are represented [28-30]. The interface between the different materials that make them up determines the charge transport and charge injection efficiency, with implications for the performance of the devices.

Interfacial phenomena are particularly crucial towards

\footnotetext{
${ }^{*}$ Corresponding author.
}

the development and improvement of applications of these devices and in order to effectively investigate multilayer structured devices, the overall flexibility becomes very critical. This, in addition to their molecular nature, makes the study of organic thin films interfaces to be more intensified compared to inorganic semiconductors.

The type of interaction at the interface is either physical or chemical and progress in organic electronics requires their detail understanding [31]. Investigations of the chemical nature of interfaces are common in thin film characterization, but not much attention has been directed at measuring physical interaction until recently when advanced characterization tools are becoming more widely available. However, in a work reported on the nanoscale adhesion between organic-organic, organic-inorganic, and inorganic-inorganic thin film interfaces [32], the AFM technique was used in quantifying the interfaces, though with some limitations. The pull-off forces and surface parameters were measured and incorporated into theo- 
retical models for the estimation of surface energies. Obviously, therefore, the improvement of performance of organic electronic devices depends on a clear understanding of the principles underlying organic-film/metalelectrode interfaces.

Data-storage and switching applications of conjugated polymer-based devices in which, depending on the voltage-sweep direction, two different current-voltage $(I-V)$ characteristics, and hence low and high conducting states are used, have been observed and reported (e.g. [33-39]). These devices have an associated memory effect for data-storage applications especially the bistable architectures (e.g. $[21,26,38,40-47])$. The bistable and multiple-layer stacking structures have therefore emerged as a viable technology for flexible, ultrafast, and ultrahighdensity memory devices in the field of organic electronics [48].

In a multilayer organic electronic device structure (Figure 1), charges often move from one layer to another by either injecting holes and/or electrons or transporting the same in one direction or the other. In the emissive layers, injected charges produce localized charge carrying species which move through the device under the influence of external field (bias) across the interface [49]. Charge injection transport efficiency through the interfaces is thus critical to device performance. However, there are problems of adhesion, morphological inhomogeneities and conductivity anisotropy at these interfaces which are not yet properly understood [50].

Charge transport efficiency could be enhanced by reducing the number of interfaces in organic devices. This is often done using the standard polymer processing method of blending in which organic materials, forming individual layers, are innovatively blended, thereby reducing the number of layers. This has been recognized as one of the possible ways forwarded for improved charge transport efficiency [51], as illustrated in Figure 2.

This investigation was therefore motivated by the need to explore additional interface reengineering techniques

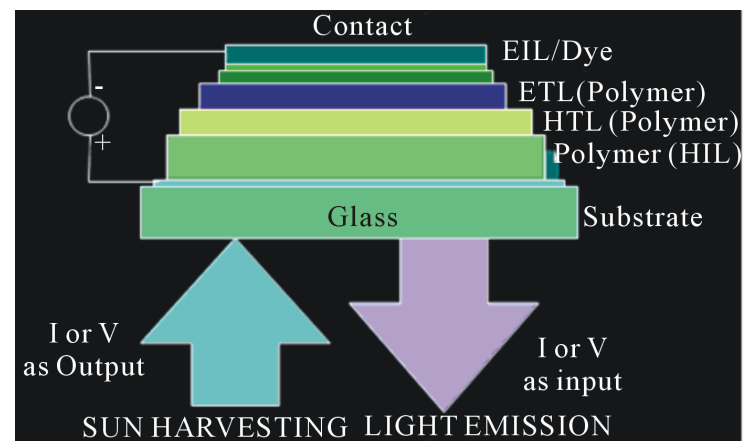

Figure 1. Typical device structure for sun harvesting (Polymer Solar Cells) and light emission (OLEDs). The figure shows the contacts and the emissive layers made up of different carefully selected conducting (conjugated) polymers.

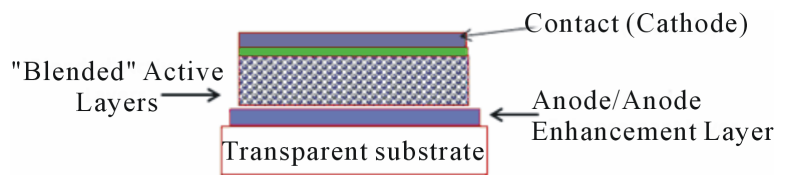

Figure 2. Device structure that reduced the number of interfaces using conventional polymer blending technique in which each phase would be expected to independently their different roles of charge transportation and injection.

using a combination of memory switching, adhesion and surface treatment. Also, this type of study could be incorporated into device performance improvement studies in view of recent reported improving power conversion efficiency of conjugated polymer-based solar cells [52], which remains largely unsatisfactory for large-scale commercial production in competition with its amorphous silicon-based devices. There are indications that charge transportation at the interface could be improved by a better understanding of the physical phenomena at the interface [32]. This has brought into the fore, an intensified investigation of the physical interaction between the dissimilar materials in direct contact, which is vital to sustainable device performance.

\section{Experimental Details}

\subsection{Materials and Equipment}

The materials used in this investigation include AL 4083 PEDOT:PSS suitable for OLED fabrication (H. C. Starck, MA, Newton, USA) as the organic layer, n-doped silicon wafer (Eagle-Picher, Miami, OK, USA) as the substrate, gold $(\mathrm{Au})$ as the metal contact layer (Alfa Aesar, USA), hydrochloric acid (Aldrich, USA) for the surface treatment of the organic layer, Hydrofluoric acid (Aldrich, USA) and standard assorted reagents for substrate cleaning. The thermal deposition of the gold contact on the organic layer was carried out using an Edwards E306A deposition system (Edwards, Sussex, UK), the switching was done with an HP semiconductor parameter analyzer (HP 4145B) for the current-voltage measurement, etched silicon contact AFM tips were purchased from Veeco Instruments (Woodbury, NY, USA), Digital Instruments Dimension 3000 Atomic Force Microscope (AFM) (Digital Instruments, Plainview, NY), Scanning Electron Microscope (SEM-EDX) (Philips FEI XL30 FEG-SEM, Hillsboro, USA), a standard Fishers ultrasonic bath, an ultra violet ozone cleaning system and a drying chamber were all used in the course of this study.

\subsection{Experimental Procedure}

A Write Once Read Many times (WORM) device was fabricated by direct spin-casting of PEDOT:PSS on a suitably cleaned $\mathrm{n}$-Si substrate followed by vacuum deposition of Au Contact. The cleaning procedure for the 
substrate includes the use of a combination of different solvents including acetone, trichloroethylene (TCE), isopropanol, hydrofluoric acid (HF), a detergent and deionized water under different temperature conditions in an ultrasonic bath. The substrate was then transferred to an ultra violet ozone cleaning system for 5 min for further cleaning after which it was transferred to a glove box for safe keeping, ready for spin coating of the organic layer.

A thin layer of PEDOT:PSS (about $500 \mathrm{~nm}$ ) determined based on standard calibration curves obtained by plotting series of spinning speeds, accelerations and thicknesses and after drying (H. C. Starck, Newton, MA USA suppliers of PEDOT:PSS) was then deposited on the substrate by spin coating in ambient air condition followed by baking in an oven at $200^{\circ} \mathrm{C}$ for about $60 \mathrm{~min}$. The sample was again transferred to a glove box ready for the Au deposition. Some of the spin-coated samples were chemically treated with dilute $\mathrm{HCl}(0.1 \mathrm{~N})$ prior to deposition of the $\mathrm{Au}$ contact (approximately $100 \mathrm{~nm}$, preceded by a thin layer, about $5 \mathrm{~nm}$, of $\mathrm{Cr}$ ) which was carried out by thermal evaporation under a vacuum of 1 $\times 10^{-6}$ Torr $(1$ Torr $=133.32 \mathrm{~Pa})$.

A selection of the Au/PEDOT:PSS/Si device was quasistatically switched or "blown" using a pulsed voltage ramp with $10 \mathrm{~ms}$ long $100 \mathrm{mV}$ steps and applied for 0.5 $4 \mathrm{~ms}$ as necessary The switching was carried out by use of current transients to change the polymer fuse (PEDOT:PSS) from a conducting ("1" or "ON") to a nonconducting ("0" or "OFF") state. Quasistatic (continuous) condition $\left(\mathrm{J} \sim 10 \mathrm{~A} / \mathrm{cm}^{2}\right): 0 \mathrm{~V}-10 \mathrm{~V}-0 \mathrm{~V}$ and rapid voltage pulsed transient condition $\left(\mathrm{J} \sim 1 \mathrm{kA} / \mathrm{cm}^{2}\right): 10 \mathrm{~V}, 2 \mu \mathrm{s}$ were used for this purpose [53,54].

The Au contact was deposited either before or after the polymer surface treatment and was carefully removed by a peeling process before and after switching. The same was done before and after polymer surface treatment. Phase imaging, surface topography and force calibration curves were obtained for the different surfaces by AFM in contact and tapping modes to quantify the physical interaction at the polymer interface using Au-coated cantilever tips. Interaction force response between the sample and cantilever tip [32,55] was measured for each sample. The surface roughness for each surface was recorded and related to adhesion data as measured by the deflection as recorded from the interaction between $\mathrm{Au}$-coated cantilever tip and the polymer surface.

The differently deposited, treated or untreated, switched or unswitched surfaces before or after peeling the Aucontact, were separately investigated by SEM/EDX to qualitatively correlate the effectiveness of the peeling process, and the relative degree of polymer-metal interface adhesion. These tips were coated with Au the complementary materials that make direct contact with the surfaces. The purpose is also to investigate whether part of the polymer peeled with the gold contact.

\section{Result and Discussion}

Figures 3 and $\mathbf{4}$ show the surface topography (Figures 3(a)-(d)) as determined by the degree of roughness obtained in the tapping mode; and the force calibration plots (Figures 3(a)-(d)) obtained in contact mode for the unswitched (Figures 4(a) and (c)) and switched (Figures 3(b) and (d)) devices when untreated (Figure 3) and treated (Figure 4). The values for the respective roughness are as shown in Table $\mathbf{1 .}$

Analysis of the force calibration curves shows that in the unswitched mode, when untreated (Figure 3(b)), the Au-coated cantilever tips dragged on the polymer surface prior to disengagement whereas, after switching, the disengagement of the tip was without dragging (Figure 3(d)). This was accompanied with a reduced adhesion force by almost $50 \%$. Upon surface treatment, this effect combined with that of switching to give the highest adhesion force in the samples under consideration with a much greater dragging prior to cantilever tip disengagement. This appears to suggest that surface treatment and switching are significant to improved interface adhesion between the Au contact and the polymer. This is expected to lead to an improvement in device performance; the next in the on-going work.

The summary of the deflection on the force calibration curve (a direct measure of adhesion force) as estimated directly from the calibration plots under different surface treatment and switching conditions, is shown in Table 2.

Figures 5 and 6 show the SEM/EDX images for an untreated surface in the unswitched state (Figure 5) and in the treated and switched state (the two extremes). Figure 5 indicates that peeling the $\mathrm{Au}$ contact from the PEDOT:PSS surface was "harder" with more of the Au remaining adhered to the polymer under similar peeling conditions.

This qualitatively suggests that adhesion force would be high. However, upon surface treatment (which is expected to make the surface to be more even, due to removal of surface peat, hence minimizing conductivity anisotropy and heterogeneity at the interface), the $\mathrm{Au}$ peeled off neatly leaving a smooth polymer surface, (Figure 6).

This study is significant in the quest to finding ways of improving the lifetimes of organic electronic devices through interface reengineering which is vital to better device performance. It has also qualitatively and quantitatively revealed the possibility of using this technique in combination with established packaging (or encapsulating methods to significantly contribute to general improvement in device performance). It was observed that peeling the gold contact in the untreated, unswitched 


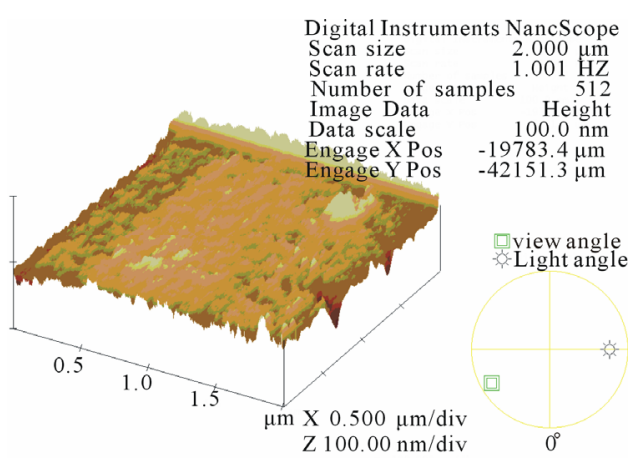

(a)

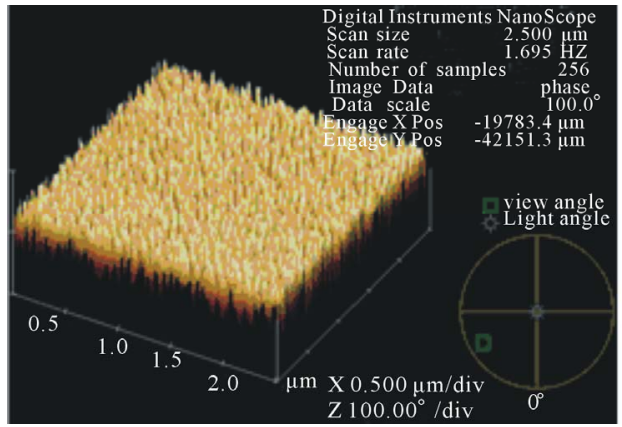

(c)

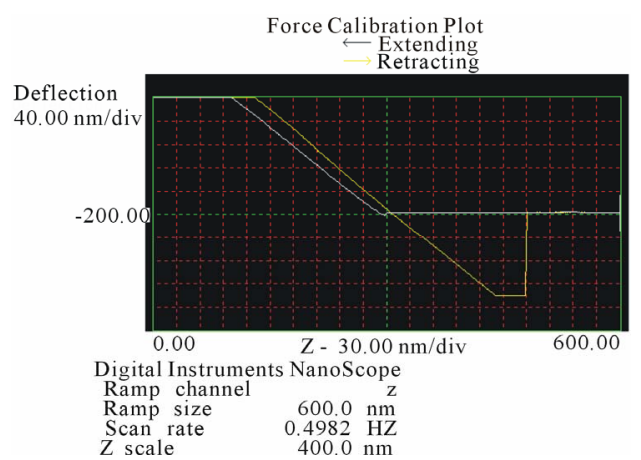

(b)

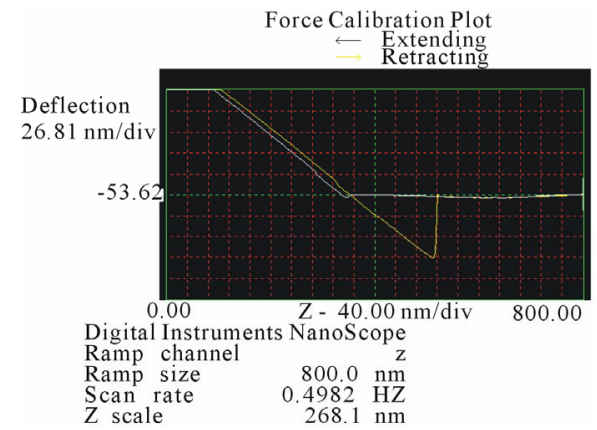

(d)

Figure 3. Surface roughness ((a) and (c)) and force displacement curves ((b) and (d)) for untreated PEDOT:PSS on silicon substrate when in the unswitched ((a), (b)) and switched ((c), (d)) modes. (a) Surface roughness in the untreated and unswitched mode; (b) Force-displacement curve in untreated and unswitched mode; (c) Surface roughness in the untreated and switched mode; (d) Force-displacement curve in the untreated and switched mode.

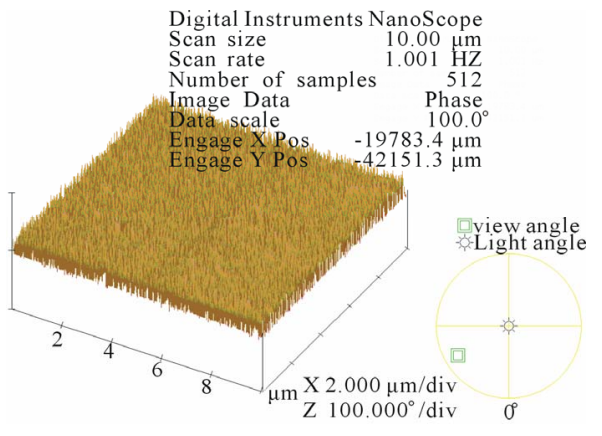

(a)

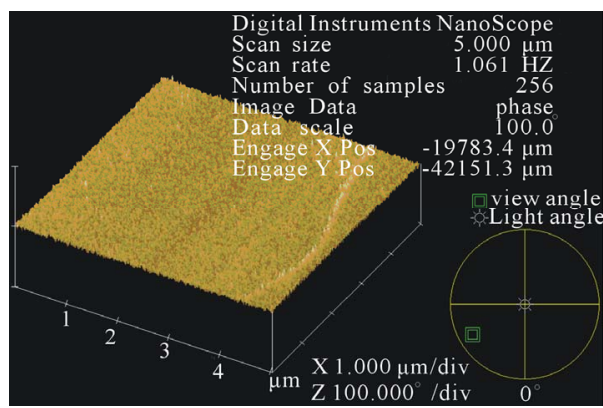

(c)

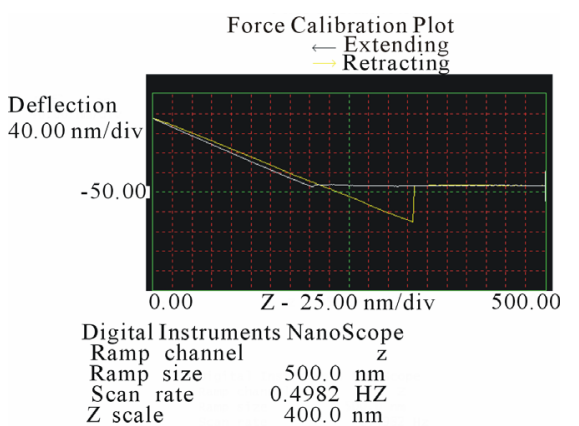

(b)

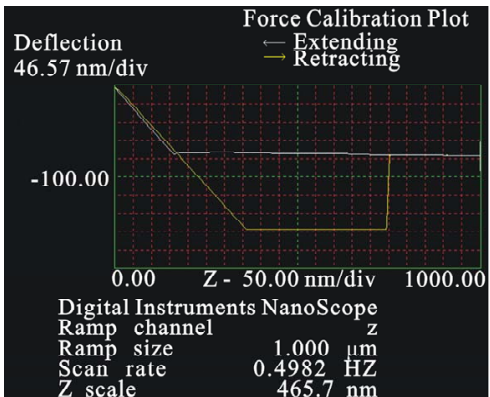

(d)

Figure 4. Surface roughness ((a) and (c)) and force displacement curves ((b) and (d)) for untreated PEDOT:PSS on silicon substrate when in the unswitched ((a), (b)) and switched ((c), (d)) modes. (a) Surface roughness in the treated and unswitched mode; (b) Force-displacement curve in the treated and unswitched mode; (c) Surface roughness in the treated and switched mode; (d) Force-displacement curve in the treated and switched mode. 


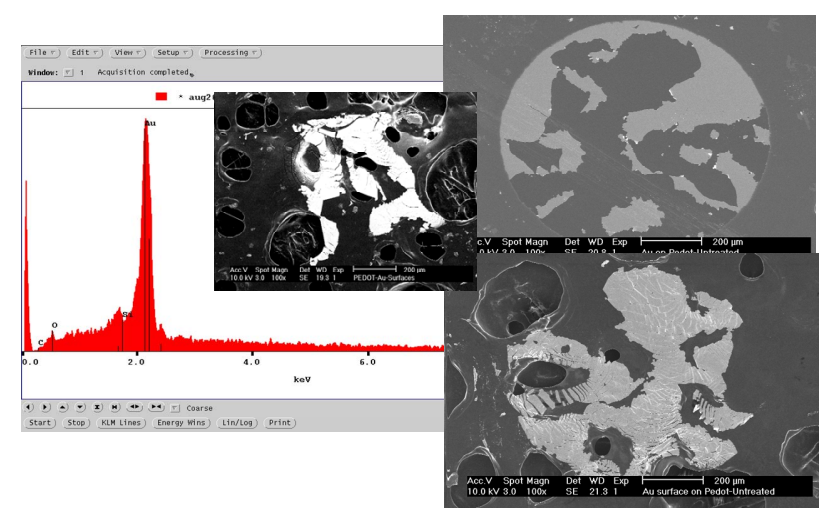

Figure 5. SEM/EDX images for an Untreated sample in the unswitched mode showing the surface of PEDOT:PSS after peeling off the Au contact (top and bottom right), the Au surface (inset) and the EDX for the contact showing that no polymer adhered to it.

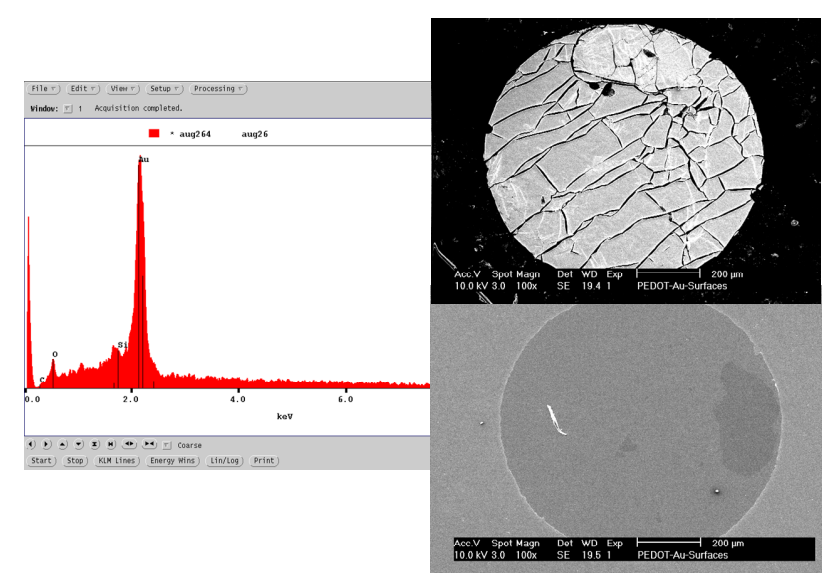

Figure 6. SEM/EDX images for an treated sample in the switched mode showing the surface of PEDOT:PSS after peeling off the Au contact (bottom right), the Au surface (top right) and the EDX for the contact showing that no polymer adhered to it.

Table 1. Summary data showing the effect of surface treatment and switching on the Au-PEDOT:PSS interface adhesion.

\begin{tabular}{|c|c|c|c|}
\hline & Unswitched & Switched & Adhesion Force \\
\hline Untreated & $\begin{array}{c}\text { Rough } \\
(13.667 \mathrm{~nm})\end{array}$ & $\begin{array}{c}\text { Smooth } \\
(5.609 \mathrm{~nm})\end{array}$ & Increased \\
\hline Treated & $\begin{array}{c}\text { Rough } \\
(9.739 \mathrm{~nm})\end{array}$ & $\begin{array}{l}\text { Smooth } \\
(1.434 \mathrm{~nm})\end{array}$ & Increased \\
\hline $\begin{array}{c}\text { Adhesion } \\
\text { Force }\end{array}$ & $\begin{array}{c}\text { Not } \\
\text { Significant }\end{array}$ & $\begin{array}{l}\text { Significant } \\
\text { Increase }\end{array}$ & \\
\hline
\end{tabular}

sample was "harder" compared to the switched and treated samples that peeled more easily with the highest interface adhesion. Since this is more or less an exploratory study, the concept of switching especially the effect of treating the surface with different reagents requires
Table 2. Summary of adhesion data showing deflection values.

\begin{tabular}{|c|c|c|c|}
\hline \multicolumn{2}{|c|}{ Untreated } & \multicolumn{2}{|c|}{ Treated } \\
\hline Unswitched & $140.00 \mathrm{~nm}$ & Unswitched & $70.00 \mathrm{~nm}$ \\
\hline Switched & $78.00 \mathrm{~nm}$ & Switched & $185.50 \mathrm{~nm}$ \\
\hline \multicolumn{2}{|c|}{ Unswitched } & \multicolumn{2}{|c|}{ Switched } \\
\hline Treated & $70.00 \mathrm{~nm}$ & Treated & $185.50 \mathrm{~nm}$ \\
\hline Untreated & $140.00 \mathrm{~nm}$ & Untreated & $78.00 \mathrm{~nm}$ \\
\hline
\end{tabular}

further detailed investigation.

The quantitative analysis of the micrographs consistently showed convincingly that there was no evidence of the presence of the polymer, PEDOT:PSS, on the gold surface as all the specimens investigated showed that each time the $\mathrm{Au}$ contact was peeled, no polymer adhered to it (Figures 5 and 6). The adhesive force at the interface is thought to be a combination of Van Der Waal and electrostatic forces in view of the involvement of different interacting ions from the reagent used in surface treatment together with that of the polyelectrolyte dopant in PEDOT. The physics and chemistry of the interaction are thus very crucial to further understanding of this phenomenon as it would complement this initial result of the study.

\section{Conclusions}

From this preliminary investigation, it can be suggested that

1) Surface treatment, switching and surface roughness all appear to be key factors in increasing interface adhesion, hence device performance.

2) Switching an untreated PEDOT:PSS surface resulted in reduced interface adhesion.

3) Switching a surface-treated specimen significantly increased interface adhesion most probably because of reduced surface roughness.

These results require more detailed investigations, especially in relation to the actual device performance.

\section{Acknowledgements}

The authors wish to acknowledge the invaluable assistance offered by staff of the nano-fabrication laboratory, Department of Electrical Engineering, Princeton University, New Jersey, USA. BB acknowledges the authorities of Obafemi Awolowo University for kindly granting leave of absence for the Fellowship at Princeton University where the experimental work was carried out.

\section{REFERENCES}

[1] M. Grobosch and M. Knupfer, "Electronic Properties of 
Organic Semiconductor/Electrode Interfaces: The Influence of Contact Contaminations on the Interface Energetic," The Open Applied Physics Journal, Vol. 4, No. 1, 2011, pp. 8-18.

http://dx.doi.org/10.2174/1874183501104010008

[2] W. Brütting, "Physics of Organic Semiconductors," WILEYVCH Verlag, Weinheim, 2005. http://dx.doi.org/10.1002/3527606637

[3] H. Klauk, "Organic Electronics," WILEY-VCH Verlag, Weinheim, 2007.

[4] K, Walzer, B. Maennig, M. Pfeiffer and K. Leo, "Highly Efficient Organic Devices Based on Electrically Doped Transport Layers," Chemical Reviews, Vol. 107, No. 4, 2007, pp. 1233-1271. http://dx.doi.org/10.1021/cr050156n

[5] N. Koch, "Organic Electronic Devices and Their Functional Interfaces," ChemPhysChem, Vol. 8, No. 10, 2007, pp. 1438-1455. http://dx.doi.org/10.1002/cphc.200700177

[6] H. Ishii, K. Sugiyama, E. Ito and K. Seki, "Energy Level Alignment and Interfacial Electronic Structure at Organic/ Metal and Organic/Organic Interfaces," Advanced Materials, Vol. 11, No. 8, 1999, pp. 605-608. http://dx.doi.org/10.1002/(SICI)1521-4095(199906)11:8< 605::AID-ADMA605>3.0.CO;2-Q

[7] A. Kahn, N. Koch and W. Gao, "Electronic Structure and Electrical Properties of Interfaces between Metals and $\pi$-Conjugated Molecular Films," Journal of Polymer Science Part B, Vol. 41, No. 21, 2003, pp. 2529-2548. http://dx.doi.org/10.1002/polb.10642

[8] J. C. Scott, "Metal-Organic Interface and Charge Injection in Organic Electronic Devices," Journal of Vacuum Science \& Technology A, Vol. 21, No. 3, 2003, pp. 521533. http://dx.doi.org/10.1116/1.1559919

[9] M. Knupfer and H. Peisert, "Electronic Properties of Interfaces between Model Organic Semiconductors and Metals," Physica Status Solidi A, Vol. 201, No. 6, 2004, pp. 1055-1074. http://dx.doi.org/10.1002/pssa.200304332

[10] M. Knupfer and G. Paasch, "Origin of the Interface Dipole at Interfaces between Undoped Organic Semiconductors and Metals," Journal of Vacuum Science \& Technology A, Vol. 23, No. 4, 2005, pp. 1072-1077. http://dx.doi.org/10.1116/1.1885021

[11] N. Koch, "Energy Levels at Interfaces between Metals and Conjugated Organic Molecules," Journal of Physics: Condensed Matter, Vol. 20, No. 18, 2008, Article ID: 184008.

http://dx.doi.org/10.1088/0953-8984/20/18/184008

[12] S. Braun, W. R. Salaneck and M. Fahlman, "EnergyLevel Alignment at Organic/Metal and Organic/Organic Interfaces," Advanced Materials, Vol. 21, No. 14-15, 2009 , pp. $1450-1472$.

http://dx.doi.org/10.1002/adma.200802893

[13] J. Hwang, A. Wan and A. Kahn, "Energetics of MetalOrganic Interfaces: New Experiments and Assessments of the Field," Materials Science and Engineering R, Vol. 64, No. 1-2, 2009, pp. 1-31. http://dx.doi.org/10.1016/j.mser.2008.12.001

[14] Y. Gao, "Surface Analytical Studies of Interfaces on Or- ganic Semiconductor Devices," Materials Science and Engineering R, Vol. 68, No. 3, 2010, pp. 39-87. http://dx.doi.org/10.1016/j.mser.2010.01.001

[15] C. W. Tang and S. A. VanSlyke, "Organic Electroluminescent Diodes," Applied Physics Letters, Vol. 51, No. 12, 1987, pp. 913-915. http://dx.doi.org/10.1063/1.98799

[16] J. Blochwitz, T. Fritz, M. Pfeiffer, et al., "Interface Electronic Structure of Organic Semiconductors with Controlled Doping Levels," Organic Electronics, Vol. 2, 2001, pp. 97-104.

http://dx.doi.org/10.1016/S1566-1199(01)00016-7

[17] K. Müllen and U. Scherf, "Organic Light Emitting Devices," WILEY-VCH Verlag, Weinheim, 2006.

[18] Y. Fukuda, W. Teruichi, W. Takeo, M. Satoshi and T. Masami, "An Organic LED Display Exhibiting Pure RGB Colors," Synthetic Metals, Vol. 111-112, 2000, pp. 1-6. http://dx.doi.org/10.1016/S0379-6779(99)00402-6

[19] A. Bandhopadhyay and A. J. Pal, "Large Conductance Switching and Memory Effects in Organic Molecules for Data-Storage Applications," Applied Physics Letters, Vol. 82, No. 8, 2003, pp. 1215-1217. http://dx.doi.org/10.1063/1.1555263

[20] A. Bandhopadhyay and A. J. Pal, "Large Conductance Switching and Binary Operation in Organic Devices: Role of Functional Groups," Journal of Physical Chemistry B, Vol. 107, No. 11, 2003, pp. 2531-2536. http://dx.doi.org/10.1021/jp027369q

[21] L. P. Ma, J. Liu and Y. Yang, "Organic Electrical Bistable Devices and Rewritable Memory Cells," Applied Physics Letters, Vol. 80, No. 16, 2002, pp. 2997-2999. http://dx.doi.org/10.1063/1.1473234

[22] G. Horowitz, "Organic Thin Film Transistors: From Theory to Real Devices," Journal of Materials Research, Vol. 19, No. 7, 2004, pp. 1946-1962. http://dx.doi.org/10.1557/JMR.2004.0266

[23] W. Clemens, I. Fix, J. Ficker, A. Knobloch and A. U11mannn, "From Polymer Transistors toward Printed Electronics," Journal of Materials Research, Vol. 19, No. 7, 2004, pp. 1963-1971. http://dx.doi.org/10.1557/JMR.2004.0263

[24] S. Scheinert and G. Paasch, "Fabrication and Analysis of Polymer Field Effect Transistors," Physica Status Solidi A, Vol. 201, No. 6, 2004, pp. 1263-1301. http://dx.doi.org/10.1002/pssa.200404335

[25] F. Cicoira and C. Santato, "Organic Light Emitting Field Effect Transistors: Advances and Perspectives," Advanced Functional Materials, Vol. 17, No. 17, 2007, pp. 34213427. http://dx.doi.org/10.1002/adfm.200700174

[26] C. D. Dimtrakopoulos and D. J. Mascaro, "Organic Thin Film Transistors: A Review of Recent Advances," IBM Journal of Research and Development, Vol. 45, No. 1, 2001, pp. 11-27. http://dx.doi.org/10.1147/rd.451.0011

[27] X. Qui, Y. Hu, G. Dong, L. Wang, J. Xei and Y. Ma, "Water Effect on the Stability of Organic Thin Film Field Effect Transistors (OTF-FET)," Applied Physics Letters, Vol. 83, 2003, pp. 1644-1646. http://dx.doi.org/10.1063/1.1604193

[28] V. Dediu, M. Murgia, F. C. Matacotta, C. Taliani and S. 
Barbanera, "Room Temperature Spin Polarized Injection in Organic Semiconductor," Solid State Communications, Vol. 122, No. 3, 2002, pp. 181-184. http://dx.doi.org/10.1016/S0038-1098(02)00090-X

[29] W. J. M. Naber, S. Faez and W. G. av der Wiel, "Organic Spintronics," Journal of Physics D: Applied Physics, Vol. 40, No. 12, 2007, pp. R205-R228. http://dx.doi.org/10.1088/0022-3727/40/12/R01

[30] Z. H. Xiong, D. Wu, Z. V. Vardeny and J. Shi, "Giant Magneto-Resistance in Organic Spin-Valves," Nature, Vol. 427, 2004, pp. 821-824. http://dx.doi.org/10.1038/nature02325

[31] C. Santato and F. Rosei, "Organic/Metal Interfaces Seeing Both Sides, News and Views," Nature Chemistry, Vol. 2, No. 5, 2010, p. 344. http://dx.doi.org/10.1038/nchem.636

[32] T. Tong, B. Babatope, S. Admassie, J. Meng, O. Akwogu, W. Akande and W. O. Soboyejo, "Adhesion in Organic Electronic Structures," Journal of Applied Physics, Vol. 106, No. 8, 2009, Article ID: 083708. http://dx.doi.org/10.1063/1.3246786

[33] J. R. de Lima, L. O. Péres, J. R. Garcia, J. Gruber and I. A. Hümmelgen, "Poly(acettoxy-p-phenylene vinylene) Based Diode with a Soft Breakdown," Solid-State Electronics, Vol. 44, No. 33, 2000, pp. 565-570. http://dx.doi.org/10.1016/S0038-1101(99)00290-7

[34] H. Carchano, R. Lacoste and Y. Segui, "Bistable Electrical Switches in Polymer Thin Films," Applied Physics Letters, Vol. 19, No. 19, 1971, pp. 414-415. http://dx.doi.org/10.1063/1.1653751

[35] B. Villeret and M. Nechtschein, "Memory Effects in Conducting Polymers," Physical Review Letters, Vol. 63, No. 12, 1989, pp. 1285-1287. http://dx.doi.org/10.1103/PhysRevLett.63.1285

[36] T. C. Chung, J. H. Kaufman, A. J. Heeger and F. Wudl, "Charge Storage in Doped Poly(Thiophene): Optical and Electrochemical Studies," Physical Review B, Vol. 30, No. 2, 1984, pp. 702-710. http://dx.doi.org/10.1103/PhysRevB.30.702

[37] V. Cimrová and D. Neher, “Anomalous Electrical Characteristics, Memory Phenomena and Microcavity Effects in Polymeric Light-Emitting Diodes," Synthetic Metals, Vol. 76, No. 1-3, 1996, pp. 125-128. http://dx.doi.org/10.1016/0379-6779(95)03434-L

[38] D. Ma, M. Aguiar, J. A. Freire and I. A. Hümmelgen, “Organic Reversible Switching Devices for Memory Applications," Advanced Materials, Vol. 12, No. 14, 2000, pp. 1063-1066.

[39] D. M. Taylor and C. A. Mills, "Memory Effect of the Current-Voltage Characteristic of a Low-Band Gap Conjugated Polymer," Journal of Applied Physics, Vol. 90, No. 1, 2001, pp. 306-309.

http://dx.doi.org/10.1063/1.1379564

[40] S. Moller, S. R. Forrest, C. Perlov, W. Jackson and C. Tausig, "Electrochromic Conductive Polymer Fuses for Hybrid Organic/Inorganic Semiconductor Memories," Journal of Applied Physics, Vol. 94, No. 12, 2003, pp. 7811-7819. http://dx.doi.org/10.1063/1.1627482
[41] H. L. Gomes, A. R. V. Benvenho, D. M. de Leeuw, M. Colle, P. Stallinga, F. Verbakel and D. M. Taylor, "Switching in Polymeric Resistance Random-Access Memories (RRAMS)," Organic Electronics, Vol. 9, No. 1, 2008, pp. 119-128. http://dx.doi.org/10.1016/j.orgel.2007.10.002

[42] H. S. Majumdara, A. Bolognesi and A. J. Pal, "Switching and Memory Devices Based on a Polythiophene Derivative for Data-Storage Applications," Synthetic Metals, Vol. 140, No. 2-3, 2004, pp. 203-206. http://dx.doi.org/10.1016/S0379-6779(03)00377-1

[43] J. R. Koo, S. W. Pyo, J. H. Kim, S. Y. Jung, S. S. Yoon, T. W. Kim, Y. H. Choi and Y. K. Kim, "Current-Voltage $(I-V)$ Characteristics of the Molecular Electronic Devices Using Various Organic Molecules," Synthetic Metals, Vol. 156, No. 2-4, 2006, pp. 298-301. http://dx.doi.org/10.1016/j.synthmet.2005.12.012

[44] J. S. Chen and D. G. Ma, "Single-Layer Organic Memory Devices Based on N,N'-Di(Naphthalene-l-yl)-N,N'-Diphenyl-benzidine," Applied Physics Letters, Vol. 87, No. 2, 2005, Article ID: 023505.

http://dx.doi.org/10.1063/1.1992653

[45] T. Graves-Abe and J. C. Sturm, "Programmable Organic Thin-Film Devices with Extremely High Current Densities," Applied Physics Letters, Vol. 87, No. 13, 2005, pp. 133502-133503. http://dx.doi.org/10.1063/1.2058219

[46] Y. S. Lai, C.-H. Tu, D.-L. Kwong and J. S. Chen, "Bistable Resistance Switching of Poly(N-Vinylcarbazole) Films for Nonvolatile Memory Applications," Applied Physics Letters, Vol. 87, No. 12, 2005, p. 122101. http://dx.doi.org/10.1063/1.2051801

[47] T. Oyamada, H. Tanaka, K. Matsushige, H. Sasabe and C. Adachi, "Switching Effect in Cu:TCNQ Charge TransferComplex Thin Films by Vacuum Codeposition," Applied Physics Letters, Vol. 83, No. 6, 2003, pp. 1252-1255. http://dx.doi.org/10.1063/1.1600848

[48] Y. Yang, J. Ouyang, L. Ma, R. J.-H. Tseng and C.-W. Chu, "Electrical Switching and Bistability in Organic/Polymeric Thin Films and Memory Devices," Advanced Functional Materials, Vol. 16, No. 8, 2006, pp. 1001-1014. http://dx.doi.org/10.1002/adfm.200500429

[49] G. G. Wallace, P. C. Dastoor, D. L. Officer and C. O. Too, "Conjugated Polymers: New Materials for Photovoltaics," Chemical Innovation-Enabling Science, Vol. 30, No. 1, 2000, pp. 14-22.

[50] M. Fahlman and W. R. Salaneck, "Surfaces and Interfaces in Polymer-Based Electronics," Surface Science, Vol. 500, No. 1-3, 2002, pp. 904-922. http://dx.doi.org/10.1016/S0039-6028(01)01554-0

[51] F. Cacialli and M. Stoneham, "Polymer Electronics: The Skill Lies in the Blending," Journal of Physics: Condensed Matter, Vol. 14, No. 47, 2002, pp. 9-11. http://dx.doi.org/10.1088/0953-8984/14/47/401

[52] D. Kozanogiu, D. H. Apaydin, A. Cirpan and E. N. Esenturk, "Power Conversion Efficiency Enhancement of Organic Solar Cells by Addition of Gold Nanostars, Nanorods and Nanospheres," Organic Electronics, Vol. 14, No. 7, 2013, pp. 1720-1727.

[53] C. D. Muller, A. Falcou, N. Reckefuss, M. Rojahn, V. Wiederhirn, P. Rudati, H. Frohne, O. Nuyken, H. Becker 
and K. Meerholz, "Multicolor Organic Light-Emitting Displays by Solution Processing," Nature, Vol. 421, 2003, pp. 829-833. http://dx.doi.org/10.1038/nature01390

[54] S. Moller, C. Perlov, W. Jackson, C. Tausig and S. R. Forrest, "A Polymer/Semiconductor Write-Once-Read-Many Times Memory," Nature, Vol. 426, 2003, pp. 166-169.

http://dx.doi.org/10.1038/nature02070
[55] O. Akogwu, D. Kwabi, S. Midturi, M. Eleruja, B. Babatope and W. O. Soboyejo, "Large Strain Deformation and Cracking of Nano-Scale Gold Films on PDMS Substrate," Materials Science and Engineering B, Vol. 170, No. 1-3, 2010, pp. 32-40.

http://dx.doi.org/10.1016/j.mseb.2010.02.023 